\title{
Diet, Diabetes Status, and Personal Experiences of Individuals with Type 2 diabetes Who Self-Selected and Followed a Low Carbohydrate High Fat diet
}

This article was published in the following Dove Press journal: Diabetes, Metabolic Syndrome and Obesity: Targets and Therapy

\section{Christopher C Webster (D) \\ Tamzyn E Murphy \\ Kate M Larmuth (iD) \\ Timothy D Noakes (D) \\ James A Smith (D)}

Division of Exercise Science and Sports Medicine, University of Cape Town, Cape Town, South Africa
Correspondence: Christopher C Webster

Division of Exercise Science and Sports Medicine, University of Cape Town, Sports Science Institute of South Africa, Newlands, Cape Town 7700, South Africa Email wbschr002@myuct.ac.za
Background: Low carbohydrate high fat (LCHF) diets are increasing in popularity amongst patients with type 2 diabetes (T2D), however it is unclear what constitutes a sustainable LCHF diet in a real-world setting.

Methods: This descriptive multi-method study characterized the diets, T2D status, and personal experiences of individuals with T2D who claimed to have followed an LCHF diet for at least 6 months. Participants completed a medications history, mixed-method dietary assessment, provided a blood sample, and were interviewed in-depth about their experiences with the diet (First-Assessment). Past medical records were obtained corresponding to T2D diagnosis and prior to starting their LCHF diets. Additionally, participants were followed up 15 months later to assess T2D remission (Follow-Up).

Results: Twenty-eight participants completed First-Assessment and 24 completed FollowUp. Habitual carbohydrate intake was 20 to $50 \mathrm{~g} / \mathrm{d}$ for 10 participants and 50 to $115 \mathrm{~g} / \mathrm{d}$ for 17 participants. Commonly reported foods were full-fat dairy, non-starchy vegetables, coconut oil, eggs, nuts, olives and avocados, olive oil, and red meat and poultry with fat. Median (interquartile range) for HbAlc was 7.5 (6.5-9.5) \% prior to starting their diets, 5.8 (5.4-6.2) \% at First-Assessment and 5.9 (5.3-6.6) \% at Follow-Up. Reported body weight and glucose-lowering medication requirements were considerably lower at both assessments than when starting the diet. At Follow-Up, 24 participants had been following their LCHF diets for 35 (26-53) months, the majority of which were in full or partial T2D remission. Participants perceived reduced hunger and cravings as one of the most important aspects of their diets. Of concern, many participants felt unsupported by their doctors.

Conclusion: This study described the foods and characteristics of an LCHF "lifestyle" that was sustainable and effective for certain T2D patients in a real-world setting.

Keywords: carbohydrate restriction, diabetes remission, ketogenic diet, LCHF, nutritional therapy, food addiction

\section{Plain Language Summary}

Until recently, low carbohydrate high fat (LCHF) diets were not supported by most T2D dietary guidelines, and the high fat component of these diets is still controversial due to concerns over long-term health outcomes. Despite this, there are a growing number of individuals following their own version of an LCHF diet to manage their T2D. The aim of this study was to characterize the diets, health, and personal experiences of individuals with T2D who claimed to have followed an LCHF diet for at least the previous 6 months.

A total of 28 participants completed the study and 24 of these participants were assessed for a second time after 15 months. We found that: 
- Average total carbohydrate intake was 61 grams per day;

- Commonly reported foods included non-starchy vegetables, full-fat dairy, meat (with fat), coconut oil, nuts, eggs, olives, olive oil and avocados;

- Highly processed foods, fruit, grains, breakfast cereals, oats, pasta, rice, beans and legumes, starchy vegetables, and vegetable and canola oil were amongst the least commonly reported foods;

- Participants had large improvements in glucose control and body weight while following their LCHF diets, which occurred in conjunction with reduced glucoselowering medication requirements;

- Eight participants discontinued insulin therapy;

- The majority of participants were in full or partial remission from T2D at the time of the second assessment;

- Participants perceived reduced hunger and cravings as one of the most important aspects of their diets but they felt unsupported by their doctors.

This study described the foods and characteristics of an LCHF "lifestyle" that was sustainable and effective for certain T2D patients in a real-world setting.

\section{Introduction}

Type 2 diabetes mellitus (T2D) is a complex disease that results from myriad genetic, environmental, and lifestyle factors that interact over many decades. It is strongly associated with obesity and cardiovascular disease and is often described as a chronic progressive disease, in which glycemic control and health are expected to decline gradually without medications. ${ }^{1}$ The primary goals of standard treatment are to reduce weight in overweight or obese patients and to reduce hyperglycemia to within an individualized target range, usually $\mathrm{HbA} 1 \mathrm{c}$ below $7 \%$, via lifestyle changes and glucose lowering medications. ${ }^{1,2}$ In recent years, there has been growing interest to not only delay the progression of T2D but also in reversing the condition. ${ }^{3,4}$ Remission from T2D with standard treatment is rare ${ }^{5}$ but occurs with greater frequency after bariatric surgery ${ }^{6}$ and severe calorie restriction ( $850 \mathrm{kcal}$ per day or less). ${ }^{7}$ More recently, severe carbohydrate restriction has also gained attention due to the potential for T2D remission. ${ }^{3,8,9}$

There has been much scientific interest in carbohydrate restricted diets to manage $\mathrm{T} 2 \mathrm{D}$, with at least 22 randomized control trials, 10 non-randomized control trials, and 10 systematic reviews ( 9 with meta-analyses) that have investigated the effects of carbohydrate restriction on glycemic control in patients with T2D. ${ }^{10-13}$ While there is considerable heterogeneity in findings, this evidence generally shows that the lower carbohydrate dietary interventions are at least as effective as control diets for improving $\mathrm{HbAlc}$, T2D medication requirements, body weight, and dyslipidemia. ${ }^{10-13}$ However, the prescribed low carbohydrate diet interventions varied considerably amongst individual studies and ranged from less than $20 \mathrm{~g}$ of carbohydrate per day to less than $50 \%$ of total energy intake. ${ }^{13}$ Interventions also varied considerably in other ways, such as recommended sources of dietary fat and protein, ad libitum versus prescribed energy intake, timing of meals, level of participant support, and duration. Further, the actual diets consumed by participants in these studies was often very different to the one prescribed by the intervention. ${ }^{12}$ Indeed, a common criticism of carbohydrate restricted diets, particularly those which target less than $50 \mathrm{~g}$ of carbohydrate per day, is that they are difficult to sustain over the long term. ${ }^{12}$

The heterogeneity in carbohydrate restricted interventions has made it difficult to assimilate findings into clear and consistent public messages. This has been a source of frustration for clinicians and confusion for patients. Despite this, carbohydrate restricted diets have grown in popularity with numerous anecdotal reports emerging of individuals having "reversed" their T2D. Individuals who have followed their own version of a carbohydrate restricted diet, rather than one which was prescribed, supported, and incentivized by an intervention trial, have rarely been studied. It is therefore largely unknown what actually constitutes a sustainable carbohydrate restricted diet in a real-world setting. Additionally, the remission claims of these individuals have not been investigated. Studying this population would present clinicians and researchers with a better understanding of the foods, behaviors, and other health-related factors that patients feel are important, as well as provide insight into why some patients may wish to follow these diets. It may also reveal aspects of their dietary interventions that are challenging or potentially dangerous. The aim of this study was therefore to characterize the diet, eating patterns, T2D status, and personal experiences of individuals with a confirmed history of T2D who claimed to have followed a carbohydrate restricted diet for at least the previous 6 months.

\section{Methods}

\section{Compliance with Ethical Standards}

This study was approved by the University of Cape Town, Faculty of Health Sciences, Human Research Ethics Committee (REF: 608/2016). All participants were informed of the nature of the study and written informed consent was obtained before participants were enrolled in the study. 


\section{Study Design}

This was a multi-method descriptive study which investigated the habitual diets, diabetes status, and personal experiences of individuals with T2D who claimed to have followed a carbohydrate restricted diet for at least the previous 6 months. Recruitment material broadly defined the diet as one which deliberately avoided carbohydrate rich foods but did not restrict dietary fat intake. Therefore, the term low carbohydrate high fat (LCHF) diet will be used in this article to refer to the habitual diets of the participants. Participants were assessed when they enrolled in the study (FirstAssessment) and again approximately 15 months later (Follow-up). No attempts were made to alter participants' diets or behaviors at any point during this study. Copies of past laboratory blood test results from the time of diagnosis (Diagnosis) and prior to starting the LCHF diet (Pre-LCHF) were obtained from the participant or from their medical practitioners. An overview of the time points and data collected in this study is shown in Table 1.

\section{Participants}

Adult participants were eligible for inclusion if they had previously been diagnosed with $\mathrm{T} 2 \mathrm{D}$ by a medical practitioner, claimed to be currently following an LCHF diet, and at least 6 months had passed since they started following their diet (Start-LCHF; Table 1). Participants were excluded from the study if they had changed their diet significantly within the past 6 months, their T2D diagnosis could not be confirmed either with past medical records or T2D medication prescriptions, or they were unable to understand and speak English. Participants were respondents to social media adverts, a press release, or posters placed at local clinics.

\section{Data Collection}

At First-Assessment, participants completed health and lifestyle questionnaires, a detailed medications history, a food frequency questionnaire (FFQ), a $24 \mathrm{hr}$ food recall, a 3-day diet record, and an in-depth one-on-one interview (Table 1). Eighteen participants lived in the Cape Town area and visited the laboratory for their interviews and food recalls. Additionally, height and weight were measured and a blood sample was drawn for HbAlc (Lancet Laboratories, South Africa). Ten participants were unable to visit the laboratory and they completed their interviews and food recalls via Skype and had their blood test with their medical practitioner. At Follow-up, participants repeated the FFQ and medications history and had $\mathrm{HbAlc}$ measured as described above.

\section{Diet Assessment}

The types of foods eaten by participants during the 6 months prior to First-Assessment and Follow-up were estimated using a 110-item semi-quantitative FFQ. This FFQ was adapted from the South African Medical Research Council (MRC) FFQ to include LCHF foods. Nutrient composition and energy intakes were quantified

Table I Definition and Measures of the Time Points in the Study

\begin{tabular}{|c|c|c|}
\hline Time Point & Description & Measures \\
\hline Diagnosis & Medical records with proof of T2D diagnosis. & - HbAlc from medical records \\
\hline Pre-LCHF & Medical records prior to starting the LCHF diet. & - HbAlc from medical records \\
\hline Start-LCHF & Self-reported date that participants started their LCHF diets. & $\begin{array}{l}\text { - Self-reported body weight } \\
\text { - Medications history }\end{array}$ \\
\hline First-Assessment & Participants were enrolled in the study and assessed. & $\begin{array}{l}\text { - Blood draw for HbAlc } \\
\text { - Body weight } \\
\text { - Medications history } \\
\text { - Food frequency questionnaire } \\
\text { - I-day diet recall } \\
\text { - 3-day diet logbook } \\
\text { - In-depth interviews }\end{array}$ \\
\hline Follow-Up & Participants were reassessed approximately 15 months later. & $\begin{array}{l}\text { - Blood draw for HbAlc } \\
\text { - Body weight } \\
\text { - Medications history } \\
\text { - Food frequency questionnaire }\end{array}$ \\
\hline
\end{tabular}

Abbreviations: T2D, type 2 diabetes; LCHF, low carbohydrate high fat. 
at First-Assessment using 4 sequential days (3 weekdays and 1 weekend day) of dietary intake data that included a 1-day food recall and 3 days of food records. The food recall was interview-based and used open-ended questions and visual aids to guide the participant on quantifying all foods and drinks consumed during the previous day. This also served as familiarization for participants to keep a detailed record of all foods and drinks consumed over the next 3 days. Nutrient composition from the food recall and 3-day record were analyzed using the MRC SAFOODS database. Some LCHF foods, for example fullfat and double-cream dairy, and bone broth, did not appear in this database. Nutrient information for these foods was obtained from either the FatSecret or NutritionDataSelf online databases. Total fat, carbohydrate, protein and alcohol composition data was available for all foods. As such, reported values for these 4 macronutrients indicate an estimate of actual intake. Fiber, sugar, fatty acid composition, and/or cholesterol content was not available in some of the missing foods. As such, reported values of these nutrients indicate an estimate of minimum intake. Micronutrient data was not available for most of the missing foods. In addition, vitamin and mineral supplementation and added salt was not recorded. The reported micronutrient data therefore represents an underestimate of intake. Diets were categorized as very low if they contained less than $50 \mathrm{~g} / \mathrm{d}$ of carbohydrate, low if they had 50 to $130 \mathrm{~g} / \mathrm{d}$ of carbohydrate, and moderate if if they had greater than $130 \mathrm{~g} / \mathrm{d}$ of carbohydrate. ${ }^{14}$

\section{In-Depth Interviews}

Individual in-depth interviews followed a semi-structured interview guide. The interviews and subsequent thematic analysis were conducted by researchers CW and TM, who had received extensive training in qualitative interview techniques and had conducted several pilot interviews prior to the start of data collection. Particular attention was placed on asking open-ended questions and probes, remaining neutral throughout the interviews, and avoiding leading questions. Participants were informed that: the interviews would be confidential; that they should speak freely and honestly about their opinions; and that there were no right or wrong answers. All interviews were audio recorded.

\section{Qualitative Analysis and Data Reporting}

The thematic analysis method was used to identify, analyze, and report emergent themes from the interviews, as described by Braun and Clarke (2006). ${ }^{15}$ This method is commonly used to analyze qualitative data and produces a rich description of the data by identifying and examining patterns of meaning (ie themes). Briefly, audio-recorded interviews were transcribed intelligent verbatim (excluding fillers such as "um"). Authors CW and TM read through all the transcripts to become familiar with the whole dataset and to check the accuracy of the transcripts against the original audio recordings. Codes (labels used to identify concepts which were relevant to participants' experiences with the LCHF diet) were developed. Sentences and passages in the transcripts were then organized and categorized based on these codes. Inter-coder reliability between $\mathrm{CW}$ and $\mathrm{TM}$ was established by independently coding $6(20 \%)$ interviews, with an accuracy of $97 \%$ and a mean kappa of $0.74 \pm 0.24 .^{16}$ The remaining 22 interviews were coded by either $\mathrm{CW}$ or TM. The researchers then searched for and identified themes and subthemes across and within codes. ${ }^{15}$ Finally, the interviews were reviewed to ensure the relevance and accuracy of the identified themes and subthemes. Coding and analysis of the transcripts was performed using Nvivo 11 Pro.

Quotations from the qualitative data were selected to illustrate the emergent themes and they capture the essence of the theme. ${ }^{15}$ When reporting the prevalence of themes, quantification was avoided so as to maintain an emphasis on the perspectives of the participants. ${ }^{17}$ Quotations are shown in quotation marks. Square brackets indicate text added by the authors to provide clarity or context and an ellipsis indicates the omission of irrelevant parts of the quote. Pseudonyms are used for participant quotes with age provided in parentheses upon first use.

\section{Remission Assessment}

Complete T2D remission was defined as HbA1c of $5.7 \%$ or less without taking any diabetes medications (including metformin) at both First Assessment and Follow Up. Partial T2D remission was defined as $\mathrm{HbA} 1 \mathrm{c}$ below $6.5 \%$ without taking diabetes medications other than metformin at both First Assessment and Follow Up. ${ }^{3}$ Remissions were referred to as "potential" if these criteria were only met at Follow-Up.

\section{Statistical Analysis}

Normality of data distribution was tested using the ShapiroWilk test. Quantitative data are reported as either mean \pm SD where normally distributed or median with interquartile range (IQR) in parenthesis where not normally distributed. All data used in the comparison of multiple time points was not normally distributed. The Wilcoxon signed-ranked test 
was used for comparisons over 2 time points. The Friedman test was used for comparisons over 3 time points and if significant, post-hoc analysis was performed using the unadjusted Pairwise Wilcoxon Rank Sum tests. Statistical analyses were performed using the Python-based library SciPy and R-3.5.1 statistical software.

\section{Results}

\section{Participant Characteristics}

A total of 28 participants (14 women and 14 men) completed First Assessment. Participants were $57 \pm 10$ years of age and body mass index was $30 \pm 6 \mathrm{~kg} / \mathrm{m}^{2}$. Median time since T2D diagnosis was 7.4 (3.5-13.2) years and ranged from 6 months to 28 years (Figure 1). Median time following an LCHF diet was 14 (9-38) months and ranged from 6 months to 6 years (Figure 1). Seven participants reported starting their LCHF diet soon after T2D diagnosis, with just 24 (3-32) days between Diagnosis and Start-LCHF. They had been following the diet for 9 (7-11) months at First-Assessment (Figure 1). Two participants had been following their diets for 24 and 16 months respectively prior to their T2D diagnosis (Figure 1). These participants had normal HbAlc and fasting plasma glucose concentrations at Diagnosis and their formal $\mathrm{T} 2 \mathrm{D}$ diagnosis was based on 120 min plasma glucose concentrations during an oral glucose tolerance test. The remaining 19 participants had T2D for 9.8 (4.7-12.2) years before StartLCHF and had reported following their LCHF diets for 22 (10-38) months at First-Assessment (Figure 1). The follow-up assessment was completed $15 \pm 2$ months after First-Assessment. Two participants could not be contacted and 2 no longer followed an LCHF diet. Reasons given by the 2 participants for stopping the diets were: 1) goal weight had been achieved; and 2) work and personal difficulties led to eating junk foods. At Follow-Up, 24 participants had been following their LCHF diets for 35 (26-53) months. No adverse events or incidents of hypoglycemia were reported in the Follow-Up period.

\section{Diet}

Table 2 shows reported habitual daily energy and macronutrient intake, derived from 4 consecutive days of diet records at First-Assessment. Estimated total carbohydrate intake was $61 \mathrm{~g} / \mathrm{d}$, including at least $38 \mathrm{~g} / \mathrm{d}$ that was digestible (glycemic) and at least $14 \mathrm{~g} / \mathrm{d}$ that was fiber (Table 2). Total carbohydrate intake was between 20 and $50 \mathrm{~g} / \mathrm{d}$ (ie very low) for 10 participants, between 50 and $115 \mathrm{~g} / \mathrm{d}$ (ie low) for 17 participants, and was $142 \mathrm{~g} / \mathrm{day}$ (ie moderate) for one participant. Participants' reported diets had similar amounts of saturated fatty acids and monounsaturated fatty acids, which made up almost $90 \%$ of the $121 \mathrm{~g} / \mathrm{d}$ of fat that was reported (Table 2). The majority of

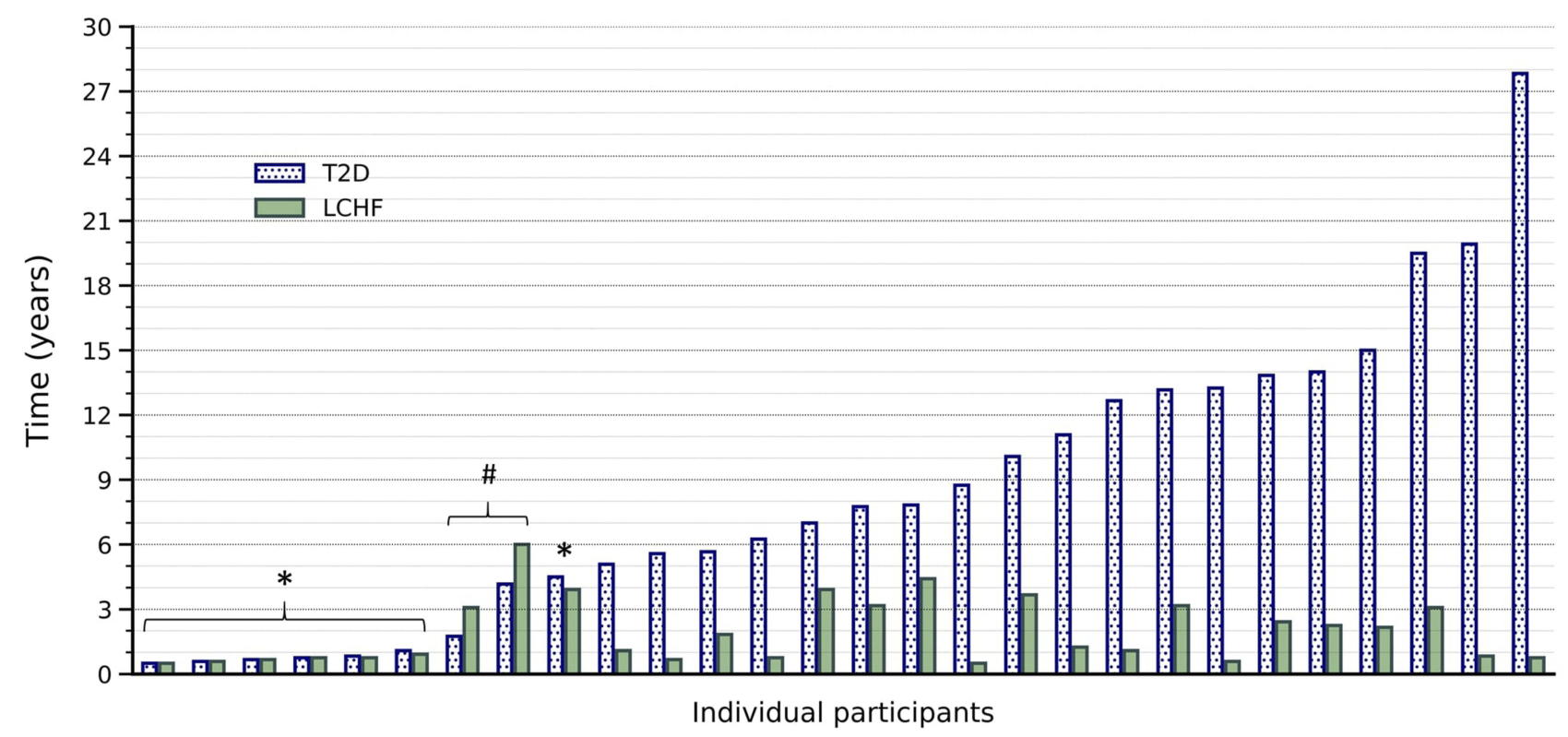

Figure I Time with T2D and time following the LCHF diet at First-Assessment. Time since diabetes diagnosis and time on the LCHF diet is shown for each individual participant at First-Assessment. Participants are ordered from left to right based on time since T2D diagnosis. *Indicates the 7 participants who started the LCHF diet shortly after diagnosis; \#Indicates the 2 participants who were following an LCHF diet prior to diagnosis. The remaining 19 participants had a period of conventional diabetes treatment prior to starting an LCHF diet. 
Table 2 Dietary Composition

\begin{tabular}{|l|l|}
\hline Energy (kcal) & $1794(1366-2474)$ \\
\hline Carbohydrate (\% energy) & $12(11-16)$ \\
\hline Carbohydrate (g) & $61(45-75)$ \\
Glycaemic (g) & $38(28-55)$ \\
Total sugar (g) & $28(17-34)$ \\
Added sugar (g) & $0(0-5)$ \\
Fibre (g) & $14(10-19)$ \\
\hline Protein (\% energy) & $20(17-23)$ \\
\hline Protein (g) & $92(67-124)$ \\
Animal sources (g) & $70(49-101)$ \\
Plant sources (g) & $8(5-12)$ \\
\hline Fat (\% energy) & $66(62-69)$ \\
\hline Fat (g) & $121(99-176)$ \\
Saturated fat (g) & $49(40-73)$ \\
MUFA (g) & $45(37-60)$ \\
PUFA (g) & $13(9-21)$ \\
Cholesterol (mg) & $616(408-799)$ \\
\hline Alcohol (g) & $0(0-11)$ \\
\hline
\end{tabular}

Notes: Reported data is from the I-day food recall and 3-day diet record. Data expressed as median (IQR). Macronutrient information was available for all foods but a further breakdown of nutrients was not available for some LCHF foods. Therefore, the nutrient breakdown for each macronutrient is incomplete and represents a minimum intake.

Abbreviations: MUFA, monounsaturated fatty acids; PUFA, polyunsaturated fatty acids.

protein was derived from animal sources (Table 2). A minimum estimate of daily vitamin and mineral intake from food sources (excluding supplementation) is reported in Table 3. Intakes of folate, vitamin D, vitamin E, and calcium were below $50 \%$ of recommended daily allowances (RDAs). Thiamin, vitamin $\mathrm{B}_{6}$, vitamin $\mathrm{C}$, magnesium, manganese, and potassium intakes were between $50 \%$ and $100 \%$ of RDAs. Intakes of the other 11 vitamins and minerals that were quantified were above the RDAs.

The FFQ was used to analyze the types of foods that participants reported eating during the months preceding First-Assessment and Follow Up. The 25 most frequently reported foods are shown in Figure 2. Dairy was one of the most reported food groups and the combined intake of cream, butter, cheese, milk, and yoghurt was 44 and 36 portions per week at First Assessment and Follow Up respectively (Figure 2). Non-starchy vegetables, coconut oil, eggs, and tree nuts were amongst the most commonly reported foods. Unprocessed red meat with fat was the most frequently reported protein. Poultry with fat, seafood, bacon, and biltong (cured, dried meat) were the other
Table 3 Vitamin and Mineral Intake

\begin{tabular}{|c|c|c|c|}
\hline & Intake & RDA & $\%$ RDA \\
\hline \multicolumn{4}{|l|}{ Vitamins } \\
\hline Vitamin A (mg/d) & $1.6(0.7-2.4)$ & 0.8 & 200 \\
\hline Thiamin $\left(B_{I}\right)(m g / d)$ & $1.0(0.6-1.3)$ & 1.2 & 83 \\
\hline Riboflavin $\left(B_{2}\right)(m g / d)$ & $1.6(1.2-2.1)$ & 1.2 & 133 \\
\hline Niacin $\left(B_{3}\right)(m g / d)$ & $20.7(16.4-26.4)$ & 15.0 & 138 \\
\hline Pantothenic acid $\left(B_{5}\right)(\mathrm{mg} / \mathrm{d})$ & $5.8(5.1-8.3)$ & $5.0 *$ & 116 \\
\hline Vitamin $B_{6}(\mathrm{mg} / \mathrm{d})$ & $1.3(0.9-1.8)$ & 1.6 & 81 \\
\hline Biotin $\left(B_{7}\right)(\mu g / d)$ & $35.5(28.7-51.9)$ & $30.0 *$ & 118 \\
\hline Folate $\left(B_{9}\right)(\mu g / d)$ & $98.2(76.9-142.6)$ & 400 & 25 \\
\hline Vitamin $B_{12}(\mu g / d)$ & $6.4(4.1-10.1)$ & 2.4 & 267 \\
\hline Vitamin C (mg/d) & $75.2(50.3-133.7)$ & 82.5 & 91 \\
\hline Vitamin D $(\mu \mathrm{g} / \mathrm{d})$ & $6.2(4.0-9.2)$ & 15.0 & 41 \\
\hline Vitamin E (mg/d) & $6.8(5.4-12.6)$ & 15.0 & 45 \\
\hline \multicolumn{4}{|l|}{ Minerals } \\
\hline Calcium (mg/d) & $502(375-679)$ & 1100 & 46 \\
\hline Copper $(\mu g / d)$ & $1.5(0.8-2.1)$ & 0.9 & 167 \\
\hline Iron (mg/d) & $10.1(8.1-13.8)$ & 8.0 & 126 \\
\hline Magnesium (mg/d) & $230(|52-3| 1)$ & 370 & 62 \\
\hline Manganese $(\mathrm{mg} / \mathrm{d})$ & $1.8(1.2-2.5)$ & $2.1 *$ & 86 \\
\hline Phosphorus (mg/d) & $1073(864-1569)$ & 700 & 153 \\
\hline Potassium (g/d) & $2.4(1.8-3.2)$ & $4.7^{*}$ & 51 \\
\hline Sodium $(g / d)$ & $1.8(1.1-2.5)$ & $1.3^{*}$ & 138 \\
\hline Zinc (mg/d) & $11.0(8.1-16.7)$ & 9.5 & 116 \\
\hline
\end{tabular}

Notes: Reported data is from the I-day food recall and 3-day diet record. Data expressed as median (IQR). Micronutrient data was not available for many LCHF foods and vitamin and mineral supplements were not captured in the study. Data therefore represents a minimum estimate of nutrient intake from food sources. RDA, Recommended Daily Allowances according to Dietary Reference Intake recommendations from the Institute of Medicine. RDAs are set 2 standard deviations above the Estimated Average Requirement for that nutrient. The reported RDA is the average for males and females aged 5I-70 years. *Indicates that Adequate Intake, a value believed to be sufficient to cover the needs of all the individuals in that category, is reported.

common protein sources. Participants predominantly reported eating fatty cuts of meat as well as full-fat dairy, whereas lean meats and low-fat dairy were rarely reported. Fruits (with the exception of olives, avocados, and berries), grains, breakfast cereals, oats, breads, pasta, rice, beans and legumes, starchy vegetables, and vegetable and canola oil were amongst the least frequently reported foods. Although most participants reported that they did not drink alcohol, some reported regular daily intakes. No participants reported adding sugar to food or drinks but non-sugar sweeteners and sugar-free soft drinks were fairly commonly reported.

\section{Medications}

Medications were reported at Start-LCHF, FirstAssessment, and Follow-Up. Most participants reported 

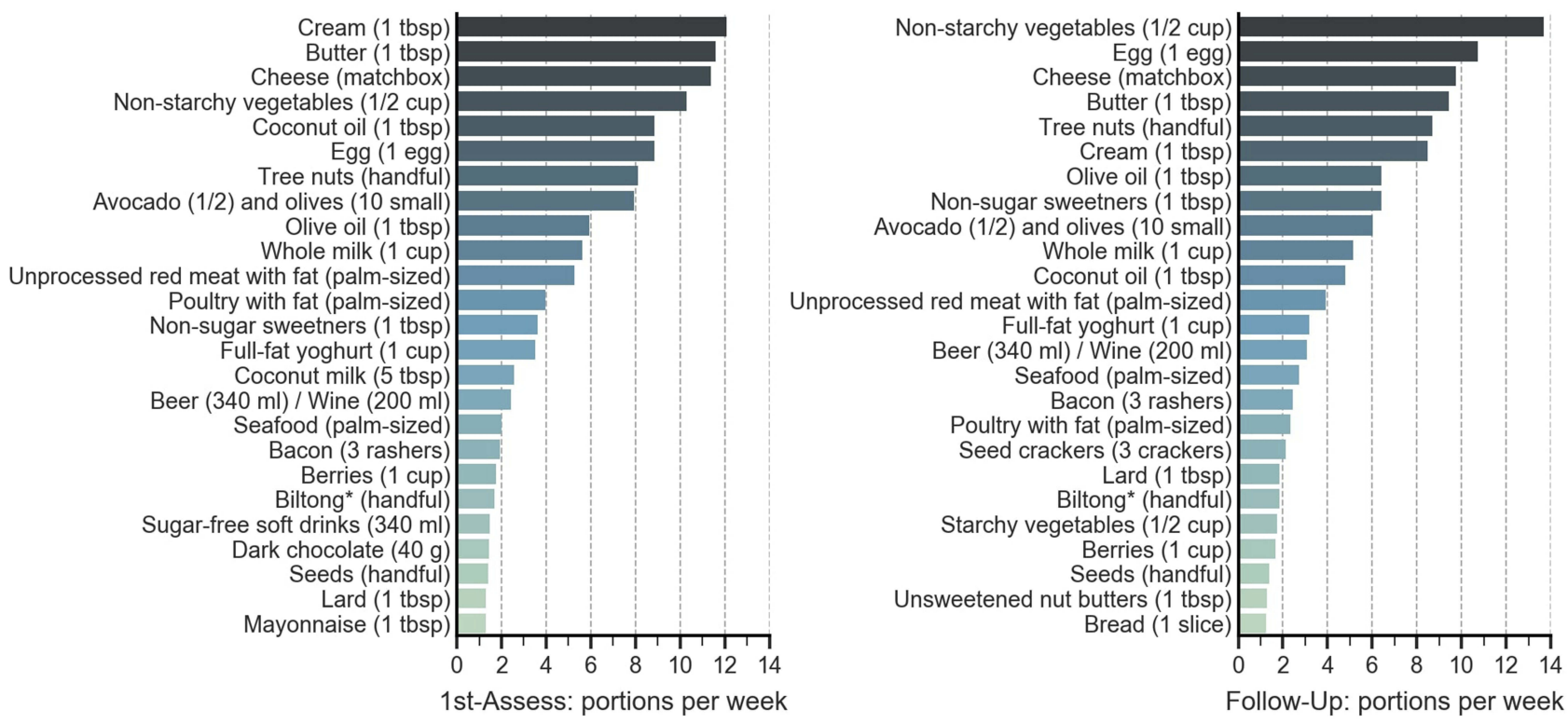

Figure 2 The 25 most frequently reported foods according to the Food Frequency Questionnaire. Data shown is from the Food Frequency Questionnaire (FFQ) completed at First-Assessment (left) and Follow-Up (right). Figure shows the reported food portions per week. Ist-Ass, First-Assessment; Tbsp, tablespoon; *Biltong is cured, dried meat, usually from beef or game.

large reductions in diabetes medications from Start-LCHF to First-Assessment. At Start-LCHF, 24 participants reported taking a median of 1850 (1000-2000) $\mathrm{mg} / \mathrm{d}$ of metformin, compared with 16 participants taking 1000 (1000-2000) mg/d at First-Assessment. There were 11 participants taking 60 (39-94) U/d of exogenous insulin at Start-LCHF. At First-Assessment, 8 participants reported that they had discontinued insulin completely, 2 reported reduced doses ( 88 to $26 \mathrm{U} / \mathrm{d}$ and 40 to $32 \mathrm{U} / \mathrm{d}$ respectively), and 1 remained unchanged at $48 \mathrm{U} / \mathrm{d}$. There were 2 participants using sulphonylureas at Start-LCHF and by First-Assessment, 1 had discontinued and the other had reduced their dose. The only other diabetes medication reported at Start-LCHF was a DPP-4 inhibitor used by one participant, which was discontinued by First-Assessment. Amongst all 28 participants, there was only 1 case of an increase in diabetes medications from Start-LCHF to FirstAssessment, where 1 participant started a sulphonylurea. There were only minor changes in reported diabetes medications at Follow-Up compared to First-Assessment: 2 participants discontinued metformin; 1 decreased metformin dose; 1 increased metformin dose; 1 discontinued a sulphonylurea; 1 started a sulphonylurea and DPP-4 inhibitor; and 1 started a GLP-1 receptor agonist and SGLT2 inhibitor. In terms of cholesterol-lowering medications (statins), 14 participants reported that they were taking statins at Start-LCHF. Of these 14 participants, 1 reported a prior cardiovascular disease event (a stroke). By First-Assessment, 7 participants had discontinued statins and 1 additional participant had discontinued statins by Follow-Up. Therefore, 6 participants were taking statins at Follow-Up, including the 1 participant who had a prior cardiovascular disease event.

\section{$\mathrm{HbAlc}$}

There were 22 participants with HbAlc data at Pre-LCHF, First-Assessment, and Follow-Up (Figure 3A). The participants missing from this comparison were the 4 lost at Follow-Up and the 2 who started the diet prior to Diagnosis and therefore did not have a Pre-LCHF record. HbA1c in these 22 participants was 7.5 (6.5-9.5) \% at PreLCHF, 5.8 (5.4-6.2) \% at First-Assessment and 5.9 (5.3-6.6) \% at Follow-Up (Figure 3A). These 22 participants were further analyzed in two subgroups: 6 participants who started their LCHF diets soon after diagnosis (Figure $3 \mathrm{~B}$ ); and 16 who had T2D for an extended period prior to Start-LCHF (Figure 3C). This analysis was done as those participants who started their LCHF diets soon after Diagnosis were unaware of their diabetes at the time of the reported $\mathrm{HbA1c}$ values and none were taking glucose lowering medications (Figure 3B). By contrast, the 16 participants in Figure 3C were aware of their T2D status and Pre- $L C H F$ values represent a managed state which included medications. The majority of medication changes described 

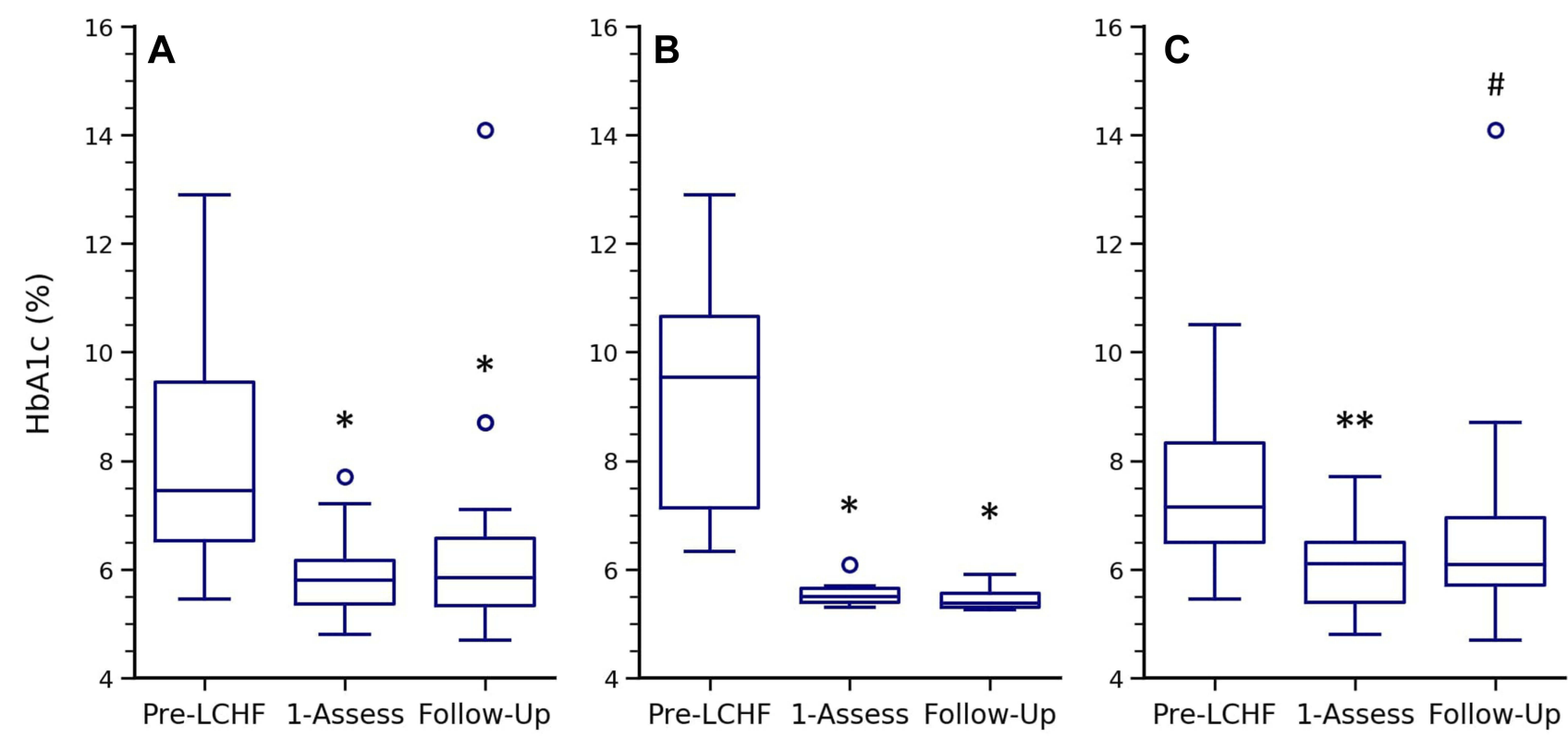

Figure 3 Change in $\mathrm{HbAlc}$ over time. HbAlc expressed as median, interquartile ranges, and outliers at Pre-LCHF, First-Assessment and Follow-Up for: (A) all participants with valid $\mathrm{HbAl}$ c records at these three timepoints $(n=22, p<0.0 \mathrm{I})$; (B) the subset of participants who started LCHF shortly after diagnosis $($ Pre-LCHF is equivalent to Diagnosis) $(n=$ $6, p<0.01$ ); and $(C)$ the subset of participants who were receiving conventional T2D management prior to starting an $L C H F$ diet $(n=16, p=0.03)$. $P$ values were determined using the Friedman test. *and **Indicates a significant difference to Pre-LCHF ( $<<0.05$ and $<0.01$ respectively); ${ }^{\#}$ Indicates that the $\mathrm{p}$ value for the difference between Pre-LCHF and FollowUp changes from 0.08 to 0.02 if analyzed without the 14 . I\% outlier. Post hoc $p$ values were determined using the unadjusted pairwise Wilcoxon post-hoc test.

above, including all of the reductions in exogenous insulin, were in this second subgroup. Therefore, the $\sim 1 \%$ reduction in $\mathrm{HbAlc}$ from Pre-LCHF to First-Assessment occurred in conjunction with these medication reductions (Figure $3 \mathrm{C}$ ). In those that started the diet soon after Diagnosis, HbAlc was 9.5 (7.1-10.7) \% at Diagnosis, 5.5 (5.4-5.7) \% at FirstAssessment and 5.4 (5.3-5.6) \% at Follow-Up (Figure 3B). In the participants who were aware of their diabetes at the time of the Pre-LCHF record, HbAlc was 7.1 (6.5-8.3) \% at Pre-LCHF, 6.1 (5.4-6.5) \% at First-Assessment and 6.1 (5.7-7.0) \% at Follow-Up (Figure 3C). One participant had a notable deterioration in $\mathrm{HbA} 1 \mathrm{c}$, which increased to $14.1 \%$ at Follow-Up (Figure $3 \mathrm{~A}-\mathrm{C}$ ). The reason for this was unclear and he reported at Follow-Up that he was struggling with a variety of health and personal issues. Median HbAlc for all 28 participants at First-Assessment was 5.6 (5.3-6.1) $\%$. There was no significant change in HbA1c in the 24 participants still following the diet at Follow-Up $(p=0.48)$.

\section{Weight Loss}

Self-reported weight loss was 16 (7-31) kg from StartLCHF to First-Assessment $(\mathrm{p}<0.001)$ and there was no change in body weight from First-Assessment to Follow-Up ( $\mathrm{p}=0.64)$ (Figure 4A). All 28 participants reported weight loss from Start-LCHF to FirstAssessment and median weight loss as a percentage of weight at Start-LCHF was 17 (7-25) \%. At Follow-Up, there were 10 participants who had sustained weight losses of more than $25 \mathrm{~kg}$ for $3.5 \pm 1.3$ years, including 4 participants who had lost over $50 \mathrm{~kg}$. Weight loss was larger in the participants who had T2D for a prolonged period prior to starting the LCHF diet than in those who started the diet shortly after T2D diagnosis (Figure 4B and $\mathrm{C}$ ). The number of participants in body mass index (BMI) categories of normal weight $\left(<25 \mathrm{~kg} / \mathrm{m}^{2}\right) /$ overweight $\left(25-30 \mathrm{~kg} / \mathrm{m}^{2}\right) /$ obesity $\left(30-40 \mathrm{~kg} / \mathrm{m}^{2}\right) /$ and severe obesity (BMI $>40 \mathrm{~kg} / \mathrm{m}^{2}$ ) was: $3 / 5 / 11 / 9$ at Start-LCHF; 4/14/9/1 at First-Assessment; and 6/10/8/0 at FollowUp.

\section{Diabetes Remission}

Of the 24 participants tested at Follow-Up: 7 were in complete $\mathrm{T} 2 \mathrm{D}$ remission $(\mathrm{HbA} 1 \mathrm{c}<5.7 \%$ and no $\mathrm{T} 2 \mathrm{D}$ medications at First Assessment and Follow-Up); 3 were in potential complete remission (they met the definition of complete remission at Follow-Up but partial remission at First-Assessment); and 7 were in partial remission $(\mathrm{HbA} 1 \mathrm{c}<6.5 \%$ and taking no T2D medications other than metformin at First-Assessment and FollowUp). Seven participants were not in remission as they were taking glucose lowering medications in addition to 

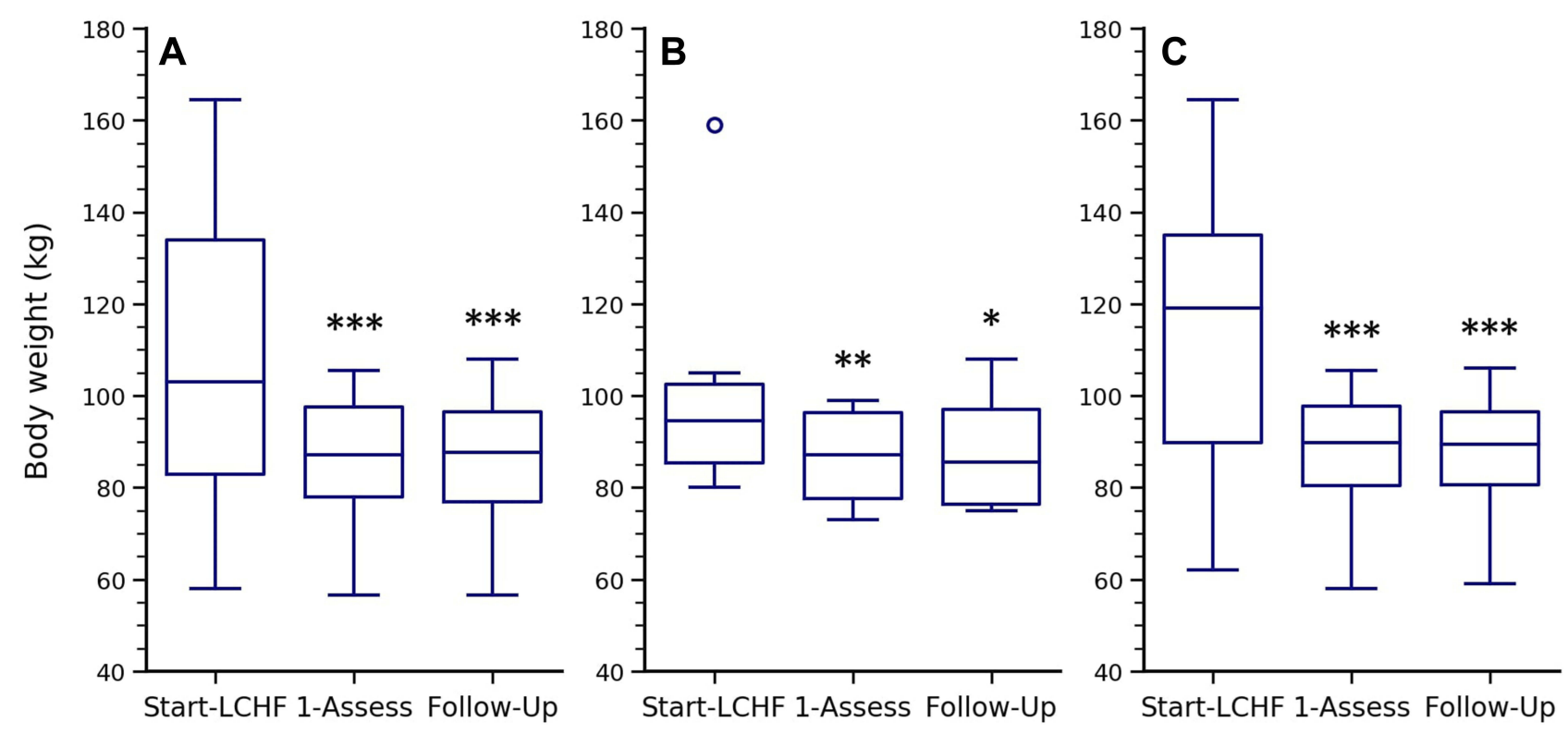

Figure 4 Body weight at Start-LCHF, First-Assessment and Follow-Up. Body weight expressed as median, interquartile ranges, and outliers at Start-LCHF, First-Assessment and Follow-Up for: $(\mathbf{A})$ all participants who completed Follow-Up $(n=24, p<0.00 I) ;(B)$ the subset of participants who started LCHF shortly after diagnosis $(n=6, p=$ 0.03 ); and C) the subset of participants who were receiving conventional T2D management prior to starting an LCHF diet $(n=16, p<0.00 I)$. $P$ values were determined using the Friedman test. *,**, and $* * *$ Indicates a significant difference to Start-LCHF $(\mathrm{p}<0.05,0.0 \mathrm{I}$, and $0.00 \mathrm{I}$ respectively); Post hoc $\mathrm{P}$ values were determined using the unadjusted pairwise Wilcoxon post-hoc test.

metformin and/or had HbAlc greater than $6.5 \%$ at Follow-Up.

\section{Interview Analysis}

The duration of interviews ranged from 21 to $64 \mathrm{~min}$, with an average length of $38 \mathrm{~min}$. Four themes, comprising 13 subthemes, were identified during the thematic analysis and are reported in Table 4. Findings from each theme are presented below.

\section{Control of Eating}

A majority of participants reported experiencing reduced hunger since following their LCHF diets. The sentiment of "not getting hungry" was often contrasted against previous diets or weight loss attempts where they felt they were "always hungry". John (58) said of his previous diet: "I was low GI, low fat, hungry 24/7. Every time I ate, I was thinking about my next meal, I dreamt of food." Similarly, Peter (48) compared his previous "balanced diet" to his current LCHF diet, saying: "I remember waking up chewing on my earplug. I was so hungry that in a dream I thought: 'This is food.' The biggest difference when introducing the fat was that the hunger was sated." When they did get hungry, participants described experiencing a milder form of hunger, rather than an urgent "need" to eat. Susan (59) said:
"When I got hungry [prior my LCHF diet], it wasn't: 'I think I would like to eat something now', it was: 'if I don't eat something now, I'll die!'” Most participants spoke of how they had developed an awareness of their hunger over time, which resulted in organic changes in eating behaviors. The most commonly described changes were less frequent meals and a reduction or

Table 4 Themes and Sub-themes Identified from the in-Depth Interviews

\begin{tabular}{|l|l|}
\hline Themes & Sub-Themes \\
\hline Control of eating & $\begin{array}{l}\text { Reduced hunger } \\
\text { Reduced cravings for sweetness } \\
\text { Less frequent meals and snacks } \\
\text { Preference for whole foods } \\
\text { Easy to sustain }\end{array}$ \\
\hline Control of health & $\begin{array}{l}\text { Empowered and increased } \\
\text { positivity } \\
\text { Increased quality of life } \\
\text { Increased energy levels }\end{array}$ \\
\hline Social eating & $\begin{array}{l}\text { Reduced enjoyment } \\
\text { Negativity from public/ } \\
\text { acquaintances }\end{array}$ \\
\hline $\begin{array}{l}\text { Interactions with medical } \\
\text { professionals }\end{array}$ & $\begin{array}{l}\text { Participant independence } \\
\text { Apathy of doctors } \\
\text { Conflict over some medications }\end{array}$ \\
\hline
\end{tabular}


complete cessation of snacking. Megan (51) described this process: "I got to the stage where I don't actually feel like this egg in the morning .... It was probably after about a month [on my LCHF diet] that I stopped eating breakfast in the mornings before work." Most participants said they now ate 1 or 2 meals per day. "I stuck to [previous meal times] and then realized, you shouldn't be eating if you are not hungry. So, I pushed my breakfast later and found I wasn't hungry," said Kim (63). Similarly, Andrew (65) said:

I realized, hang on, I am getting it wrong. I am eating because it is meal time. I am not eating because I am hungry and I am really following the same bad patterns. I am just changing what is on the plate.

A powerful "craving" for sweetness was described by many participants as driving uncontrolled eating prior to starting their LCHF diets. Since starting their LCHF diets, participants found that their taste for sweetness had changed and many described no longer feeling "tempted", "bothered", "triggered", or "turned-on" in situations such as shopping aisles and/or parties with cakes, sweets, and baked goods. Mary (66) described this process as "breaking the sugar barrier" and Nicola (67) said of her experiences with sugar: "I miss the sweet stuff. But the less you have of it the less you want." Several participants identified themselves as carbohydrate or sugar addicts, such as Dean (65) who said: "I have come to understand with low carb, that I'm an addict. Carbs are something that I'm probably never going to be able to eat for the rest of the life." These participants described how they felt that total elimination of certain foods was their only option. "If I have 1 biscuit, it becomes 3 biscuits, it becomes the rest of the packet," said John (58). Similarly, Peter said: "Not having bread at all, I could cope with, but having one piece of bread was just infuriating and difficult for me." Participants were "wary" of all sweet-tasting foods, including those low in carbohydrate - a category of foods predominantly made up of low-carbohydrate products and substitute foods. According to Angus (67):

I took one bite [of a low carb product] and it was just full of xylitol and very, very sweet. Immediately I wanted to eat the whole thing, and I would have had that, and another one. That was the immediate response.

The majority of participants spoke of their diets in terms of whole foods and said they avoided processed foods and/or food products. Victoria (49) said: "If its got a label,
I generally tend to avoid it." Similarly, Heather (67) said: "I don't eat anything that comes from a box or a tin where I have to read the ingredients." The potential for hidden ingredients in food products was raised as a specific concern by some participants.

Almost all participants felt that the ease with which they could sustain their LCHF diets was key to their success. Participants did not feel "deprived" or that willpower was required to maintain control of their eating. Many participants emphasized that it was the first time they had lost weight without hunger. Robert (46) said:

I've never been able to lose weight for more than a few months [before LCHF] and I've been at LCHF for almost a year now, so I would say I'm going to eat that way for the rest of my life.

Several participants mentioned that not measuring quantities or counting calories contributed towards the ease of following their diets. Andrew described his diet as "exceptionally sustainable" and Kim said: "The first two weeks is not so nice, but thereafter, just amazing and I will never go back." When talking about sustainability, many participants specifically referred to their LCHF diets as a "lifestyle" rather than a diet. "I think people hear the word diet, suggesting it's something that you do short term .... So, it's a way of living rather than a diet. I think that distinction is important," said Gregory (49). Only two participants doubted the sustainability of their diets. Nicola said: "It takes out much of the joy for me at this stage. I remember being very sorry for myself when I started with LCHF. I couldn't freely partake in everything anymore," and Victoria said: "The centimeters are going but the kilograms are not falling as fast. I must say, I am sitting at a stage where I think a lot of people are saying, 'Is this the right thing?"'

\section{Control of Health}

The majority of participants described their primary motivation for starting an LCHF diet as either to control their T2D or to reduce T2D medications (insulin in particular). Weight loss was of secondary importance to most participants but there were a few for whom it was the primary motivation for the diet. Every participant said their T2D had improved since following their LCHF diets and they described their diabetes with phrases such as: "under control"; "gone"; "no trace of it"; "doesn't exist"; "has not progressed"; and "definitely improving". 
According to Stephen (56): "It cured my diabetes, that's for sure. I am diabetes free now. As long as I keep doing LCHF, I have no diabetes anymore." Participants felt increased control, confidence, and a sense of accomplishment at having improved their health. Andrea (63) said: "[I am] very positive in the fact that I feel more under control. That I can do this by diet - I really do not want to go onto medications." Tom (46) expressed similar sentiments when he said: "All I can say is that it's an amazing, positive feeling .... I eat right, I drink less medication, and I'm still weaning myself off it. So that's a huge positive." Participants who reduced their medications, stopped or reduced injecting insulin, or felt they had avoided starting insulin, described these outcomes as extremely empowering and motivating. In addition to improvements in $\mathrm{T} 2 \mathrm{D}$, the majority of participants experienced weight loss and described being surprised by unanticipated health improvements. Often it was something that had bothered them for years that had improved or disappeared. Every individual had a different experience and the wide variety of health improvements described by participants included: skin and skin conditions; headaches; general pain; joint pain; neuropathy pain; fertility; cramping; gout; sleep; and hypertension. According to Kim:

Knowing how good I feel health-wise and weight-wise, I would never want to go back. I wouldn't want the battles that I've had with excess weight and with diabetes particularly, and all the other health problems, which have gone. It is like being a miracle.

A few participants experienced hypoglycemic incidents when first starting the diet. These incidents were always attributed to the effects of exogenous insulin. Hypoglycemia was not mentioned as a concern under any other circumstances. The only other negative physical symptom to emerge as a theme was constipation, which was reported by a minority of participants. For most who experienced constipation, it resolved 2 to 3 weeks after starting their diets. However, one said it took longer than a year to disappear and two participants said they were still battling with constipation.

A major theme was the impact of weight loss and general health improvements on quality of life and participants described experiencing increased positivity and energy. Increased energy levels were described as both a general excitement and enthusiasm for life as well as the specific ability to focus and concentrate better. Mark
(52) said: "I'm far more positive about the future. The pain in my knees and my back have disappeared. I'm more focused and I'm able to concentrate more on a particular task." Terry (67) said: "All of a sudden I had so much energy," and others described themselves as feeling: "hyped about life"; "having more energy and a new sort of enthusiasm"; "positive about myself"; and "more alert, more awake, more alive." Michael (59) said: "I can concentrate longer and work longer. I'm more alert .... My energy levels are up as well." According to Caroline (41): "Just in terms of walking around the block with my child every day, that kind of thing, 3 or 4 years ago, you must be joking. I'd be like, do what!?" Kim said:

Before I was always sleepy and tired and just had no energy. Now I am up and clearing the house and spring cleaning and my husband is very amused - I am always active, like I used to be in my twenties.

\section{Social Eating}

The main negative aspect of their LCHF diets was that socializing was difficult. Tom said: "Having supper in a restaurant is a problem in the majority of restaurants. It's just not enjoyable anymore." Lack of appropriate foods was identified as a problem; however, a bigger concern was that participants felt conflicted over being polite versus adhering to their diets when eating with friends. Juliet (52) said: "When people are going out for dinner and they are not aware of your [eating habits], occasionally you just need to put [your diet] aside and eat what they give you." Other participants held a firmer stance. George (62) said:

The odds are, if we are going out to eat, then we've either eaten beforehand or we're not going to eat and basically have water, because it's pointless. You just can't get people to give you what you need.

Some participants' social lives were impacted to the point where they said they no longer wanted to go out, even though socializing used to be a big part of their lives. Social situations were also made difficult for some participants who said that colleagues and acquaintances held a negative attitude towards low carbohydrate diets and were often judgmental. These participants were frustrated that they received "flak" and negative comments from people they felt did not understand the improvements that LCHF eating had made to their lives. Olivia (33) 
said: "You get the frowns, the 'Why are you not eating fruit anymore? Why are you not eating sugar anymore?' So, that has been my main battle." Gregory said: "People can't put two and two together to see it's benefited me. 'You can have a heart attack if you eat all that fat.' All of those stereotypical comments do come out on occasion." Several participants said that in certain social settings, such as casual work parties, people became irritated with them and often tried pressuring them into eating sugary foods. Andrea said:

People don't understand that I am trying to [heal] without medication and I am trying to lower my sugars with diet. They will say things like, 'Oh just have a piece of cake, it won't kill you.' And inside I am saying, well actually it may just.

\section{Interactions with Medical Professionals}

Two participants said they had consulted a dietitian on how to follow an LCHF diet. The rest of the participants had received no formal education on the diet and had developed their diets on their own. The majority of participants had a good general knowledge of health and nutrition and had developed their LCHF diets using books and online material without any assistance from health professionals. Gregory reflected on this, saying: "I guess I was lucky to find and to have access to knowledge and have the right mentality to discover what I did on my own." Every participant had an active relationship with at least one medical doctor and only a small minority of participants were given direct advice to follow LCHF diets by their doctors. Robert said: "My doctor told me to go completely onto meat, poultry, oily fish, cheese, green healthy vegetables, leafy vegetables and come back and see him in three months." A majority of participants had "informed" their doctors about their diets only after they had already followed it for an extended period. Some participants had decided not to tell their doctors about their diets at all, despite having followed their diets for several years in some cases. Once informed, participants said their doctors were concerned or cautious about their diets and used phrases such as: "it is in your hands"; "if you're comfortable with it"; "well, if it works for you." Many participants said that their doctors became supportive of their efforts after they had seen good results. However, participants expressed frustration that even though their doctors were "amazed", "thrilled" or "impressed" with their results, they were still reluctant to openly discuss their LCHF diets. Michael said: "Well I think my doctor is pleased with [my results], but he obviously won't discuss [LCHF]." Heather said:

I would like to see the point where the doctors that are seeing me, the regular doctors that are seeing me, recognized the fact that I have lost weight, that I am on a strict diet, that I take responsibility for my health.

There were also a number of participants who described hostile interactions with doctors who were opposed to LCHF diets. John said: "Not one of the 7 medical persons that I interacted with supported me, not one of them." Conflict was usually related to blood cholesterol concentrations and cholesterol-lowering medications. Some participants described doubting whether they should continue with their LCHF diets after their doctors "berated" them for their cholesterol levels. Other participants were more confident in their decision to eat LCHF diets, such as Gregory who said:

The doctor tried to put me on statins and I refused. Because I'd read quite a lot of research and literature on statins and how they were, at best, probably a marginal benefit for the majority of people who took them.

Andrew said: "I made a deal with my doctors .... I am in charge of my health, not you." Jeff (72) said: "I immediately wrote to my doctors, saying, 'I have stopped statins on my own accord and I acknowledge that you have told me to take them.' They are so shit scared of the Medical Health Council." A broader theme to emerge was that most participants believed they had benefited more from their recent LCHF diets than they had from years of taking various medications. Many participants revealed how they had started questioning whether their medications were appropriate or necessary. George said: "When you get involved in reading up about what goes on, you start understanding that maybe there are things that you've been prescribed which are inappropriate." This left many participants "wondering if they couldn't reduce the meds." Many participants expressed a desire to work with their doctors to reduce medications.

\section{Discussion}

This study investigated the habitual diets and diabetes status of individuals with T2D who claimed to be following an LCHF diet. One of the aims of this study was to provide an indication of the types of foods, nutrients, and eating patterns that constituted an LCHF diet that was sustainable for individuals with T2D in a real-world setting. All but one participant followed either a very low 
$(<50 \mathrm{~g} /$ day $)$ or low $(<130 \mathrm{~g} /$ day $)$ carbohydrate diet. ${ }^{14}$ This low level of carbohydrate intake is noteworthy, given that participants were not screened for eligibility according to macronutrient intake. Their diets were also not prescribed or incentivized by a clinical trial and very few participants reported that they had input from medical professionals in developing their diets. Participants were generally well informed on publicly available LCHF information, suggesting that their diets were largely influenced by these sources of public messaging. Many participants also reported that they had developed an awareness of how all foods affected their hunger and health, irrespective of carbohydrate content. Therefore, the food and nutrient data described in this study reflects diets that had evolved for each individual, based on both their nutritional knowledge and personal experimentation.

There were a number of diet-related features other than macronutrient composition that were common amongst participants. Firstly, reported diets included predominantly unprocessed and minimally-processed whole foods according to NOVA classification, ${ }^{18}$ or processed foods like cured meat, dairy, and coconut products. Ultra-processed foods, including those specifically marketed as low carbohydrate products, were not frequently reported. Secondly, many participants naturally stopped snacking between meals and reduced the number of meals they ate each day. Thirdly, a large proportion of reported foods were from animal sources such as meat, poultry, dairy, and eggs. Finally, it is likely that participants reduced their energy intake after adopting their LCHF diets, given the large reductions in reported body weight. Many participants also reported experiencing increased energy levels and described a corresponding increase in physical activity. It is therefore not clear to what extent these dietary and non-dietary factors may have influenced the health of these participants independent of carbohydrate restriction. ${ }^{19-21}$ In order to recognize the above nuances, the term "LCHF lifestyle" may be a more appropriate way to describe the interventions of participants in the current study. These factors are also important to consider when designing and interpreting future controlled studies, especially since less frequent eating and calorie reduction may occur spontaneously with LCHF diets and increased energy levels and physical activity may occur with weight-loss.

The inclusion criteria for the current study would have favored participants that had positive health experiences with an LCHF diet and would have missed those who stopped the diet prior to 6 months. Even so, it is remarkable that so many of these participants were either in complete or partial T2D remission, given the progressive nature of the disease and the rarity of remissions with conventional treatment. ${ }^{5}$ That LCHF diets have the potential to put T2D into remission is becoming increasingly recognized, especially in trials with a high level of patient monitoring and support. ${ }^{3,8}$ The 7 participants from the current study who started their LCHF diet soon after diagnosis responded particularly well, which agrees with the notion that an LCHF diet may be especially effective for remission in newly diagnosed T2D patients or those taking less medication. ${ }^{3,14}$ The selection of highly motivated participants may explain why our findings are considerably more favorable than conclusions from a number of recent metaanalyses of RCTs. ${ }^{11-13}$ These meta-analyses generally show a small advantage of the lower carbohydrate diet for improving glycemic control, which was most prominent early in the trial but was often less defined or absent at trial end. The true efficacy of carbohydrate restriction is difficult to determine from these meta-analyses as the RCTs often had reduced dietary compliance (in both groups) over time, and included participants that did not adhere to the intervention in the analysis. ${ }^{22}$ Additionally, many of the RCTs included in the meta-analyses achieved or targeted only "moderate" carbohydrate restriction. ${ }^{13}$ An important avenue for future research should focus on maximizing dietary compliance.

There are also aspects of our participants' interventions that are particularly controversial. A large proportion of reported foods were from animal sources, including red meat and cured meats such as bacon. Saturated fat containing foods were commonly reported whereas wholegrains and fiber intake was relatively low. Although low carbohydrate eating patterns have recently been included in the ADA and EASD guidelines, the high fat component of the diet has not been endorsed. ${ }^{1,23}$ All of these features of the participants' diets have also been associated with negative health outcomes in long-term prospective cohort studies. ${ }^{24-29}$ Additionally, low carbohydrate diet patterns (generally $30-40 \%$ carbohydrate), and particularly animal-based low carbohydrate diet patterns, have been associated with increased risk of T2D incidence and mortality. ${ }^{30-33}$ The above associations from prospective cohort studies likely underpin the lack of encouragement and support that many of our participants experienced from their physicians regarding their LCHF diets. An implication of this was that many participants started their diets and/or reduced their medications without appropriate medical supervision, which is 
potentially dangerous. ${ }^{34}$ It also exposes an interesting dilemma: should a patient who has improved their T2D, lost considerable body weight, reduced their medications, and subjectively improved their quality of life with an animal-based LCHF diet, be advised to change aspects of their intervention based on population level nutritional associations? Many T2D nutritional recommendations state that patients should be supported in an individualized diet that suits their preferences and lifestyle ${ }^{35,36}$ and it is especially important that patients on glucose-lowering medications are medically supervised when first starting an LCHF diet due to the risk of hypoglycemia. Clinicians are therefore encouraged to engage openly with patients about the potential harms and benefits of LCHF diets and make decisions which consider patient values and preferences. ${ }^{37,38}$

\section{Limitations}

This was a descriptive study with a small sample size (for the quantitative component of the study) which would have selected for individuals who responded well and were able to sustain an LCHF diet. It therefore does not provide evidence that an LCHF diet is appropriate for a wider T2D population. The diets described in this study were those that participants had sustained and refined based on personal experience. As such, they do not necessarily represent an ideal LCHF diet but rather provide an indication of the types of diets being followed in a real-world setting. Much of the data are self-reported. Micronutrient data was not available for some LCHF foods and we did not record vitamin and mineral supplementation.

\section{Summary and Conclusions}

This observational study documented 28 T2D patients who reported following a self-administered LCHF diet that was rich in full-fat dairy, fatty meats, coconut oil, non-starchy vegetables, nuts, eggs, olives, olive oil, and avocados. While following their LCHF diets, HbA1c, body weight, and T2D medication requirements were dramatically reduced, with the majority of participants having achieved complete or partial T2D remission. Participants perceived reduced hunger and cravings as one of the most important aspects of their diets. Of concern, many participants felt unsupported by their doctors which may have resulted in suboptimal medical supervision. This study described the characteristics and nuances of an LCHF "lifestyle" that was sustainable and effective for certain T2D patients in a real-world setting.

\section{Compliance with Ethical Standards}

This study was approved by the University of Cape Town, Faculty of Health Sciences, Human Research Ethics Committee (REF: 608/2016). All participants were informed of the nature of the study and written informed consent was obtained before participants were enrolled in the study.

\section{Data Sharing Statement}

Supplementary data and resources are available via the University of Cape Town's Figshare account at the following link: https://doi.org/10.25375/uct.7635926

\section{Acknowledgements}

We are appreciative of Ian Rogers for his assistance with survey tools and data management practices, and of Zoe Duby for her assistance with qualitative research methods. Thank you to the participants who volunteered for this study. We thank three anonymous reviewers whose comments helped improve and clarify this manuscript.

\section{Author Contributions}

$\mathrm{CW}$ and JS were lead authors and contributed equally to this study. All authors contributed to data analysis, drafting and revising the article, gave final approval of the version to be published, and agree to be accountable for all aspects of the work.

\section{Funding}

This project was funded by the National Research Foundation of South Africa and The Noakes Foundation.

\section{Disclosure}

TN is the author of the books Lore of Running and Waterlogged and co-author of The Real Meal Revolution, Challenging Beliefs, Raising Superheroes (Superfoods for Superheroes), Lore of Nutrition, Real Food on Trial, and The Banting Pocket Guide. All royalties from the sale of books dealing with nutrition are donated to the The Noakes Foundation of which he is the Chairman and which funds research of insulin resistance, diabetes and nutrition (including this study) as directed by its Board of Directors. Money from the sale of other books is donated to the Tim and Marilyn Noakes Sports Science Research Trust which funds the salary of a senior researcher at the University of Cape Town, South Africa (research focuses on the study of skeletal muscle in African mammals and of the pathophysiology of type 2 diabetes in some such 
mammals). The other authors declare no potential conflicts of interest in this work.

\section{References}

1. American Diabetes Association. Lifestyle management: standards of Medical Care In Diabetes-2019. Diabetes Care. 2019;42(Suppl 1): S46-S60.

2. American Diabetes Association. 6. Glycemic targets: standards of Medical Care in Diabetes-2019. Diabetes Care. 2019;42(Suppl 1): S61-S70. doi:10.2337/dc19-S006

3. Hallberg SJ, Gershuni VM, Hazbun TL, Athinarayanan SJ. Reversing type 2 diabetes: a narrative review of the evidence. Nutrients. 2019;11:4

4. Forouhi NG, Misra A, Mohan V, Taylor R, Yancy W. Dietary and nutritional approaches for prevention and management of type 2 diabetes. BMJ. 2018;361:k2234. doi:10.1136/bmj.k2234

5. Karter AJ, Nundy S, Parker MM, Moffet HH, Huang ES. Incidence of remission in adults with type 2 diabetes: the diabetes \& aging study. Diabetes Care. 2014;37(12):3188-3195. doi:10.2337/dc14-0874

6. Purnell JQ, Selzer F, Wahed AS, et al. Type 2 diabetes remission rates after laparoscopic gastric bypass and gastric banding: results of the longitudinal assessment of bariatric surgery study. Diabetes Care. 2016;39(7):1101-1107. doi:10.2337/dc15-2138

7. Lean ME, Leslie WS, Barnes AC, et al. Primary care-led weight management for remission of type 2 diabetes (DiRECT): an open-label, cluster-randomised trial. Lancet. 2018;391(10120):541-551. doi:10.10 16/S0140-6736(17)33102-1

8. Athinarayanan SJ, Adams RN, Hallberg SJ, et al. Long-term effects of a novel continuous remote care intervention including nutritional ketosis for the management of type 2 diabetes: a 2-year non-randomized clinical trial. Front Endocrinol (Lausanne). 2019;10:348. doi:10.3389/fendo.2019.00348

9. Saslow LR, Summers C, Aikens JE, Unwin DJ. Outcomes of a digitally delivered low-carbohydrate type 2 diabetes self-management program: 1-year results of a single-arm longitudinal study. JMIR Diabetes. 2018;3 (3):e12. doi:10.2196/diabetes.9333

10. Hallberg SJ, Dockter NE, Kushner JA, Athinarayanan SJ. Improving the scientific rigour of nutritional recommendations for adults with type 2 diabetes: a comprehensive review of the American Diabetes Association guideline-recommended eating patterns. Diabetes Obes Metab. 2019;21(8):1769-1779. doi:10.1111/dom.2019.21.issue-8

11. Korsmo-Haugen HK, Brurberg KG, Mann J, Aas AM. Carbohydrate quantity in the dietary management of type 2 diabetes: a systematic review and meta-analysis. Diabetes Obes Metab. 2019;21(1):15-27. doi:10.1111/dom.13499

12. McArdle PD, Greenfield SM, Rilstone SK, Narendran P, Haque MS, Gill PS. Carbohydrate restriction for glycaemic control in Type 2 diabetes: a systematic review and meta-analysis. Diabet Med. 2019;36(3):335-348. doi:10.1111/dme.2019.36.issue-3

13. Huntriss R, Campbell M, Bedwell C. The interpretation and effect of a low-carbohydrate diet in the management of type 2 diabetes: a systematic review and meta-analysis of randomised controlled trials. Eur J Clin Nutr. 2018;72(3):311-325. doi:10.1038/s41430-017-0019-4

14. Feinman RD, Pogozelski WK, Astrup A, et al. Dietary carbohydrate restriction as the first approach in diabetes management: critical review and evidence base. Nutrition. 2015;31(1):1-13. doi:10.1016/ j.nut.2014.06.011

15. Braun V, Clarke V. Using thematic analysis in psychology. Qual Res Psychol. 2006;3(2):77-101.

16. McHugh ML. Interrater reliability: the kappa statistic. Biochem Med (Zagreb). 2012;22(3):276-282. doi:10.11613/issn.1846-7 482

17. Hannah DR, Lautsch BA. Counting in qualitative research: why to conduct it, when to avoid it, and when to closet it. J Manage Inq. 2011;20(1):14-22. doi:10.1177/1056492610375988
18. Monteiro CA, Cannon G, Moubarac JC, Levy RB, Louzada MLC, Jaime PC. The UN decade of nutrition, the NOVA food classification and the trouble with ultra-processing. Public Health Nutr. 2018;21 (1):5-17. doi:10.1017/S1368980017000234

19. Mattson MP, Longo VD, Harvie M. Impact of intermittent fasting on health and disease processes. Ageing Res Rev. 2017;39:46-58. doi:10.1016/j.arr.2016.10.005

20. Poti JM, Braga B, Qin B. Ultra-processed food intake and obesity: what really matters for health-processing or nutrient content? Curr Obes Rep. 2017;6(4):420-431. doi:10.1007/s13679-017-0285-4

21. Hall KD. Ultra-processed diets cause excess calorie intake and weight gain: a one-month inpatient randomized controlled trial of ad libitum food intake. NutriXiv. 2019.

22. Hebert JR, Frongillo EA, Adams SA, et al. Perspective: randomized controlled trials are not a panacea for diet-related research. Adv Nutr. 2016;7(3):423-432. doi:10.3945/an.115.011023

23. Davies MJ, D'Alessio DA, Fradkin J, et al. Management of hyperglycemia in type 2 diabetes, 2018. A Consensus Report by the American Diabetes Association (ADA) and the European Association for the Study of Diabetes (EASD). Diabetes Care. 2018;41(12):2669-2701.

24. Abete I, Romaguera D, Vieira AR, de Munain AL, Norat T. Association between total, processed, red and white meat consumption and all-cause, CVD and IHD mortality: a meta-analysis of cohort studies. Br J Nutr. 2014;112(5):762-775. doi:10.1017/S000711451400124X

25. Wang X, Lin X, Ouyang YY, et al. Red and processed meat consumption and mortality: dose-response meta-analysis of prospective cohort studies. Public Health Nutr. 2016;19(5):893-905. doi:10.1017/ S1368980015002062

26. Micha R, Michas G, Mozaffarian D. Unprocessed red and processed meats and risk of coronary artery disease and type 2 diabetes-an updated review of the evidence. Curr Atheroscler Rep. 2012;14(6):515-524.

27. Wang DD, Li Y, Chiuve SE, et al. Association of specific dietary fats with total and cause-specific mortality. JAMA Intern Med. 2016;176 (8):1134-1145.

28. Satija A, Bhupathiraju SN, Rimm EB, et al. Plant-based dietary patterns and incidence of type 2 diabetes in US men and women: results from three prospective cohort studies. PLoS Med. 2016;13(6): e1002039. doi:10.1371/journal.pmed.1002039

29. Zong G, Gao A, Hu FB, Sun Q. Whole grain intake and mortality from all causes, cardiovascular disease, and cancer: a meta-analysis of prospective cohort studies. Circulation. 2016;133(24):2370-2380. doi:10.1161/CIRCULATIONAHA.115.021101

30. Namazi N, Larijani B, Azadbakht L. Low-carbohydrate-diet score and its association with the risk of diabetes: a systematic review and meta-analysis of cohort studies. Horm Metab Res. 2017;49 (8):565-571. doi:10.1055/s-0043-112347

31. Seidelmann SB, Claggett B, Cheng S, et al. Dietary carbohydrate intake and mortality: a prospective cohort study and meta-analysis. Lancet Public Health. 2018;3(9):e419-e428. doi:10.1016/S24682667(18)30135-X

32. de Koning L, Fung TT, Liao X, et al. Low-carbohydrate diet scores and risk of type 2 diabetes in men. Am J Clin Nutr. 2011;93 (4):844-850. doi:10.3945/ajcn.110.004333

33. Fung TT, van Dam RM, Hankinson SE, Stampfer M, Willett WC, $\mathrm{Hu}$ FB. Low-carbohydrate diets and all-cause and cause-specific mortality: two cohort studies. Ann Intern Med. 2010;153 (5):289-298. doi:10.7326/0003-4819-153-5-201009070-00003

34. Murdoch C, Unwin D, Cavan D, Cucuzzella M, Patel M. Adapting diabetes medication for low carbohydrate management of type 2 diabetes: a practical guide. Br J Gen Pract. 2019;69(684):360-361. doi:10.3399/bjgp19X704525

35. Johnston BC, Kanters S, Bandayrel K, et al. Comparison of weight loss among named diet programs in overweight and obese adults: a meta-analysis. JAMA. 2014;312(9):923-933. doi:10.1001/jama.2014. 10397 
36. Asif M. The prevention and control the type- 2 diabetes by changing lifestyle and dietary pattern. J Educ Health Promot. 2014;3:1. doi:10. 4103/2277-9531.127541

37. Johnston BC, Seivenpiper JL, Vernooij RW, et al. The philosophy of evidence-based principles and practice in nutrition. Mayo Clin Proc Innov Qual Outcomes. 2019;3(2):189-199. doi:10.1016/j.mayocpiqo. 2019.02.005
38. Inzucchi SE, Bergenstal RM, Buse JB, et al. Management of hyperglycemia in type 2 diabetes: a patient-centered approach: position statement of the American Diabetes Association (ADA) and the European Association for the Study of Diabetes (EASD). Diabetes Care. 2012;35(6):1364-1379. doi:10.2337/dc12-0413

\section{Publish your work in this journal}

Diabetes, Metabolic Syndrome and Obesity: Targets and Therapy is an international, peer-reviewed open-access journal committed to the rapid publication of the latest laboratory and clinical findings in the fields of diabetes, metabolic syndrome and obesity research. Original research, review, case reports, hypothesis formation, expert opinion and commentaries are all considered for publication. The manuscript management system is completely online and includes a very quick and fair peer-review system, which is all easy to use. Visit http://www.dovepress.com/testimonials.php to read real quotes from published authors. 